cleansing and may have stemmed from a schizophrenic illness characterised by an overwhelming fear of developing syphilis; addiction subsequently occurred. The pattern of addiction was similar to that with other addictive substances, including a reluctance to admit the quantity consumed, drinking secretly alone, and consuming gradually increasing amounts. There was no information on attempts to abstain, nor were there obvious withdrawal symptoms while in hospital.

In the case reported by Joubert et al acute ingestion of $350 \mathrm{ml}$ household Dettol produced deep coma for six to eight hours, then diarrhoea for 48 hours; ultimate recovery, however, was uneventful. We could not ascertain the exact quantity that our patient was consuming, but apparently she had been regularly intoxicated for at least a year. We do not know the long-term effects of this substance, but at necropsy the liver and kidneys were normal, though the $\gamma$-glutamyltransferase activity-a sensitive index of alcoholic liver drainage-was increased.

Patients in the series of Mendelson et al were all addicted to ethyl alcohol primarily and subsequently used isopropyl alcohol because of its greater effects. The present case appears to be unique, as the addiction supervened on a morbid cleansing obsession.

We are grateful for the help of Mrs A Irwin, staff pharmacist, Royal Infirmary, Edinburgh.

${ }^{1}$ Joubert, P, Hindt, H S, and Du Toit, P, British Medical fournal, 1978, 1, 890.

2 Mendelson, J, et al, Quarterly fournal of Studies on Alcohol, 1957, 18, 561.

(Accepted 23 fanuary 1979)

Department of Clinical Surgery, Edinburgh Royal Infirmary, Edinburgh EH3 9YW

J S KHAN, MB, BS, registrar

M C WILSON, MD, FRCS, lecturer

T V TAYLOR, MD, FRCS, senior lecturer

\section{Treatment of ulcerative colitis with thalidomide}

The only generally accepted ethical use of thalidomide is in treating erythema nodosum leprosum (ENL), 1 the immune-complex complication of lepromatous leprosy. Its value has been proved by doubleblind, internally controlled trials ${ }^{2}{ }^{3}$ and it is the preferred treatment of severe chronic ENL in light-skinned male patients and postmenopausal women, being less toxic than corticosteroids. Its mode of action, however, remains uncertain.

Having observed over many years the excellent results obtained with thalidomide in ENL, a leprosarium staff member with chronic ulcerative colitis asked that she might undergo clinical trial of the drug. Since immune complexes may play a part in the pathogenesis of ulcerative colitis ${ }^{4}$ her request was accepted; we report here the results after 18 months' continuous treatment.

\section{Case report}

In October 1972 a 28 -year-old married woman with three children and a history of asthma developed abdominal pain and diarrhoea with blood and mucus in her stools. No parasites were detected, metronidazole was unhelpful, and sigmoidoscopy and barium-enema examinations confirmed the diagnosis of ulcerative colitis. She was given oral steroids, hydrocortisone-retention enemas, and sulphasalazine. Over the next four years, however, she felt continuously unwell with lassitude, abdominal pain, and chronic variable diarrhoea. She also began to have pain in the sacroiliac joints whenever oral steroids were stopped.

Before beginning thalidomide in April 1977 she felt tired and was passing three or four bloody motions a day despite treatment with prednisolone $5 \mathrm{mg}$ daily and sulphasalazine $1 \mathrm{~g}$ thrice daily. Her haemoglobin concentration was $8.9 \mathrm{~g} / \mathrm{dl}$ and white cell count $13.4 \times 10^{9} / 1\left(13400 / \mathrm{mm}^{3}\right)$. Barium-enema examination disclosed absence of haustrations from the rectum to the hepatic flexure, with extensive mucosal ulceration. Limited colonoscopy showed moderate to severe inflammation of rectal, sigmoid, and descending colonic mucosa, which exuded pus and bled easily. Representative biopsy samples were taken at $10 \mathrm{~cm}$ intervals.
Thalidomide $300 \mathrm{mg}$ daily was begun under contraceptive cover, but since there was no immediate response the dosage was increased to $400 \mathrm{mg}$ daily after five weeks. The patient then steadily improved. By eight weeks she was having only one bowel motion daily, by two and a half months macroscopic blood had disappeared, and for the last year she considered her motions to be normal, save for occasional constipation. Her general condition was very satisfactory, although she continued to have stiff fingers and back on first waking and occasional episodes of asthma. Full independent neurological and electromyographic examinations failed to detect any sign of thalidomide neuropathy. Her haemoglobin concentration was $13.2 \mathrm{~g} / \mathrm{dl}$ and white cell count $4.75 \times 10^{9} / 1$ with $8 \%$ eosinophils, probably due to the thalidomide. ${ }^{3}$ On repeat colonoscopy after six months the mucosa of the rectum, sigmoid, and descending colon looked normal, with no pus and no bleeding on instrumentation. Mucosal biopsy at comparable sites showed substantial improvement. Although severe mucosal atrophy persisted, with epithelial hyperplasia, there was only very little inflammation, which was chronic in character, the findings being graded as "chronic ulcerative colitis in remission." Prednisolone and sulphasalazine were stopped at 5 and $15 \frac{1}{2}$ months respectively and the dosage of thalidomide reduced gradually to $200 \mathrm{mg}$ daily without clinical relapse.

\section{Comment}

Ulcerative colitis is noted for its episodes of remission and exacerbation. Nevertheless, our patient's apparent response to thalidomide was impressive, since after four and a half years of ill health she became fit apart from morning joint pain and stiffness and had stopped taking steroids and sulphasalazine without any sign of relapse. A wellplanned clinical trial in carefully selected patients with moderate to severe disease not warranting surgery appears to be indicated.

We thank Dr Basil Morson for the histological reports, Dr Kannan Kutty for the histological preparations, and Dr C Balaratnam for the neurological and electromyographic examinations. The Leprosy Research Unit is jointly sponsored by the Malaysian Ministry of Health and the British Medical Research Council.

${ }^{1}$ WHO Expert Committee on Leprosy, World Health Organisation. Technical Report Series, No 607. Geneva, WHO, 1977.

2 Sheskin, J, Leprosy Review, 1965, 36, 183.

3 Waters, M F R, Leprosy Review, 1971, 42, 26

4 Jewell, D P, and MacLennan, I C M, Clinical and Experimental Immunology, 1973, 14, 219.

(Accepted 8 February 1979)

Leprosy Research Unit, National Leprosy Control Centre, Sungei Buloh, Malaysia

M F R WATERS, FRCP, FRCPATH, director (present address: National Institute for Medical Research, London NW7 1AA)

A B G LAING, MD, DTM\&H, research physician

Hospital Besar, Jalan Pahang, Kuala Lumpur 03-20

A AMBIKAPATHY, $\mathrm{MB}, \mathrm{MRCP}$, physician and lecturer in medicine (present address: The Royal Melbourne Hospital, Parkville, Victoria 3050, Australia)

St Mark's Hospital, London EC1V 2PS

J E LENNARD-JONES, MD, FRCP, consultant gastroenterologist

ONE HUNDRED YEARS AGO We are informed that the Commissioners appointed by the Home Secretary to inquire into the circumstances of the death of John Nolan in the Clerkenwell Prison have completed their investigations and prepared their report. It will be remembered that a coroner's jury recorded a verdict that this lad, who was convicted of a trivial offence and sentenced to four months' hard labour, "died from inflammation and congestion of the lungs, accelerated by repeated punishment on dry bread and water, ordered by the governor and sanctioned by the surgeon of the prison." Considerable feeling was excited; and at the inquest the Chairman of the Visiting Justices stated that their control over such punishment was now nullified. Mr Cross directed a special investigation by $\mathrm{Dr}$ Risdon Bennett (the President of the Royal College of Physicians), Dr Guy, FRS, and Dr Bristowe, senior physician of St Thomas's Hospital. The conclusions of their report are entirely adverse to the verdict; they consider that there is no evidence whatever to justify the allegation that death was accelerated in the manner stated; they acquit the governor and the medical officer of blame; and they comment severely upon the fact that the coroner did not order a post mortem examination in the case. (British Medical fournal, 1879.) 